\title{
Organocatalytic Enantioselective Conjugate Addition of Aldehydes to Maleimides in Deep Eutectic Solvents
}

\author{
Jesús Flores-Ferrándiz, Rafael Chinchilla* \\ Departamento de Química Orgánica, Facultad de Ciencias, and Instituto de Síntesis Orgánica (ISO), \\ Universidad de Alicante, Apdo. 99, 03080 Alicante, Spain
}

\begin{abstract}
The conjugate enantioselective addition of aldehydes, mainly $\alpha, \alpha$-disubstituted, to maleimides leading to enantioenriched succinimides, has been achieved in recyclable deep eutectic solvents at room temperature. Enantiomerically pure carbamatemonoprotected trans-cyclohexane-1,2-diamines are used as organocatalysts, affording high yields and up to $94 \%$ ee of the final succinimides. The product can be extracted from the deep eutectic solvent, which retains the chiral organocatalyst, allowing to reuse both solvent and catalyst.
\end{abstract}

\section{Introduction}

In the last years, enantioselective organocatalysis has shown as a crucial synthetic tool when the stereoselective preparation of compounds of interest is intended. ${ }^{1}$ Thus, the use of small chiral metal-free molecules as catalysts results environmentally advantageous if the synthetic procedure is designed to be scaled-up. However, some disadvantages still hamper the consideration of enantioselective organocatalysis as a common methodology in chemical industry. Among them are the frequent use of rather large amounts of organocatalyst, something that makes its recovery and reuse an important matter, as well as the usual necessity of employing conventional hazardous Volatile Organic Compounds (VOCs) as solvents to achieve the highest enantioselections.

Recently, attention has been focused in the use of Deep Eutectic Solvents (DESs) in organic synthesis as an alternative to VOCs. ${ }^{2}$ A DES is a combination of two or three components which interact through hydrogen bonds, forming a eutectic mixture with a melting point lower than the individual components. ${ }^{3}$ DESs are non-volatile, showing a low ecological footprint, attractive price and easy recyclability, and are nowadays promising "green" alternatives to conventional solvents.

Despite these potential advantages, the use of DESs in enantioselective organocatalyzed reactions results until now very scarce. Thus, the first reported example of an asymmetric organocatalyzed reaction in DESs employed in fact a tandem enzyme-proline derived combination. ${ }^{4}$ Only two very recent publications can be considered "purely organocatalytic", involving 9-amino-9-deoxy-epiquinine $^{5}$ and proline ${ }^{6}$ as chiral organocatalysts.

Enantioselective organocatalysis has been successfully employed for the preparation of enantioenriched succinimides, ${ }^{7}$ which are interesting compounds present in natural products and drug candidates. ${ }^{8}$ In addition, succinimides can be easily transformed into $\gamma$-lactams, ${ }^{9}$ important in the design of pharmaceutical agents. ${ }^{10}$
The most direct way of preparing enantioenriched succinimides in an organocatalytic fashion is by the enantioselective conjugate addition of carbon nucleophiles to maleimides. ${ }^{7}$ The nucleophile can be generated by deprotonation of a carbon pro-nucleophile using chiral basic amine-containing organocatalysts. However, when aldehydes are used as pro-nucleophiles, an $\alpha$-deprotonation by just an organic base is not feasible. In this case, an enamine-forming strategy using chiral organocatalysts bearing a primary or secondary amine is employed. ${ }^{11}$ Thus, many enamine-forming chiral organocatalysts have been reported for the enantioselective conjugate addition of aldehydes, to maleimides. ${ }^{12}$

We have previously reported the use of single enantiomers of carbamate-monoprotected transcyclohexa-1,2-diamines $\mathbf{1}$ as chiral organocatalyst in the conjugate addition of aldehydes, particularly the "difficult" $\alpha, \alpha$-disubstituted, to maleimides. ${ }^{12 q, 12 \mathrm{r}}$ As commented previously, a common disadvantage of an enantioselective organocatalytic procedure like this is the use of non-recoverable VOCs. We report now in this paper how DESs can be used in this enantioselective addition reaction, reusing both solvent and organocatalyst.

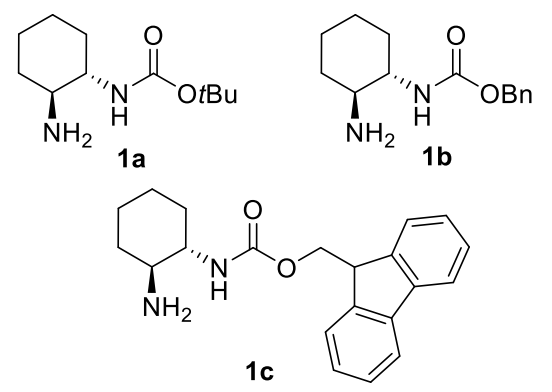




\section{Results and discussion}

The carbamate-monoprotected trans-cyclohexane-1,2diamines 1 were prepared from $(1 S, 2 S)$-cyclohexane-1,2diamine, as previously described. ${ }^{12 \mathrm{r}}$ The derivative monoprotected with the tert-butoxycarbonyl (Boc) group 1a was primarily chosen as chiral enamine-forming organocatalyst in the model enantioselective conjugate addition reaction of isobutyraldehyde (2a) to $\mathrm{N}$ phenylmaleimide (3a), in different DESs (Table 1).

Thus, the use of a $10 \mathrm{~mol} \%$ loading of $1 \mathbf{a}$ in the DES formed by choline chloride and urea $(\mathrm{ChCl} /$ urea, $1 / 2$ molar ratio, see Experimental) at room temperature, gave rise after $24 \mathrm{~h}$ to a $90 \%$ yield of succinimide $(R)-4$ aa but in only a $36 \%$ ee (Table 1 , entry 1 ). The absolute configuration was determined according to the order of elution of the corresponding enantiomers in chiral HPLC (see Experimental). ${ }^{12 \mathrm{r}}$ When the urea component of the DES was changed by glycerol $(\mathrm{ChCl} / \mathrm{Gly}, 1 / 2$ molar ratio), a higher ee for $(R)-4 a a$ was obtained $(52 \%$, Table 1 , entry 2), which resulted even higher using ethylene glycol (ChCl/ethylene glycol, 1/2 molar ratio) (64\% Table 1 , entry 3$)$, or resorcinol $(\mathrm{ChCl} /$ resorcinol, $1 / 1$ molar ratio) $(67 \%$, Table 1 , entry 4$)$.

When the employed DES was the combination of tetra- $n$-butylammonium bromide (TBAB) and Gly (TBAB/Gly, 1/3 molar ratio), $(R)$-4aa was obtained in $85 \%$ yield and $66 \%$ ee (Table 1 , entry 5 ). However, the best results were obtained using as DES the combination $\mathrm{Ph}_{3} \mathrm{MePBr} / \mathrm{Gly}(1 / 2$ molar ratio), which afforded the final adduct in $96 \%$ yield and $72 \%$ ee (Table 1, entry 6). Thus, this last DES was used in the rest of the study.

According to the literature, the presence of acid additives frequently results beneficial to this reaction. ${ }^{12 \mathrm{~b}, \mathrm{f}, \mathrm{o}, \mathrm{s}}$ Therefore, we decided to evaluate the influence of an acid component. Thus, when hexanedioic acid (HDA) was added (10 mol\%) to the reaction mixture, the reaction rate increased noticeably, as well as the enantioselection of the reaction, $(R)$-4aa being obtained in a $95 \%$ yield in only $8 \mathrm{~h}$ with an excellent $92 \%$ ee (Table 1 , entry 7). The presence of other diacids, such as oxalic or phthalic acid, as additives gave much lower yields and enantioselectivities (Table 1, entries 8 and 9). When benzoic acid was added, the reaction yield again was high and the enantioselection reached $86 \%$ (Table 1, entry 10 ). However, the addition of 3,4-dimethoxybenzoic acid allowed to achieve the best results, affording adduct $(R)$ 4aa in a $94 \%$ ee and $97 \%$ isolated yield (Table 1, entry 11). The presence of a strong electron-withdrawing group in the aromatic ring of the acid additive, as in the case of 4-nitrobenzoic acid gave slightly lower enantioselectivity (Table 1, entry 12). Moreover, the addition of bases such as imidazole or 4- $N, N$-dimethylaminopyridine (DMAP) gave good yields, but low enantioselectivities (Table 1, entries 13 and 14).

Table 1. Optimization of the reaction conditions in the model enantioselective conjugate addition in DESs.

\begin{tabular}{|c|c|c|c|c|c|c|c|}
\hline & & $\begin{array}{cc}\mathrm{Me} & \| 1 \\
2 a & \mathrm{O} \\
2 \mathrm{a} & 3 \mathrm{a}\end{array}$ & $\begin{array}{r}\begin{array}{c}\text { Catalyst } \\
\text { Additive }\end{array} \\
\text { DES, T }\end{array}$ & $4 a a$ & & & \\
\hline Entry & Catalyst (mol\%) & Additive (mol\%) & DES (molar ratio) ${ }^{\mathrm{a}}$ & $\mathrm{T}\left({ }^{\circ} \mathrm{C}\right)$ & $t(\mathrm{~h})$ & Yield $(\%)^{\mathrm{b}}$ & $e e(\%)^{\mathrm{c}, \mathrm{d}}$ \\
\hline 2 & $\mathbf{1 a}(10)$ & & $\mathrm{ChCl/Gly} \mathrm{(1/2)}$ & 25 & 24 & 94 & $51(R)$ \\
\hline 3 & $\mathbf{1 a}(10)$ & & $\mathrm{ChCl} /$ ethylene glycol $(1 / 2)$ & 25 & 24 & 46 & $64(R)$ \\
\hline 4 & $\mathbf{1 a}(10)$ & & $\mathrm{ChCl} /$ resorcinol (1/1) & 25 & 24 & 72 & $67(R)$ \\
\hline 5 & $\mathbf{1 a}(10)$ & & TBAB/Gly (1/3) & 25 & 24 & 85 & $66(R)$ \\
\hline 6 & $\mathbf{1 a}(10)$ & & $\mathrm{Ph}_{3} \mathrm{MePBr} / \mathrm{Gly}(1 / 2)$ & 25 & 24 & 96 & $72(R)$ \\
\hline 7 & $\mathbf{1 a}(10)$ & HDA (10) & $\mathrm{Ph}_{3} \mathrm{MePBr} / \mathrm{Gly}(1 / 2)$ & 25 & 8 & 95 & $92(R)$ \\
\hline 8 & $1 \mathbf{a}(10)$ & Oxalic acid (10) & $\mathrm{Ph}_{3} \mathrm{MePBr} / \mathrm{Gly}(1 / 2)$ & 25 & 8 & 28 & $72(R)$ \\
\hline 10 & $\mathbf{1 a}(10)$ & $\mathrm{PhCO}_{2} \mathrm{H}(10)$ & $\mathrm{Ph}_{3} \mathrm{MePBr} / \mathrm{Gly}(1 / 2)$ & 25 & 8 & 96 & $86(R)$ \\
\hline 11 & $\mathbf{1 a}(10)$ & $3,4-(\mathrm{OMe})_{2} \mathrm{C}_{6} \mathrm{H}_{3} \mathrm{CO}_{2} \mathrm{H}(10)$ & $\mathrm{Ph}_{3} \mathrm{MePBr} / \mathrm{Gly}(1 / 2)$ & 25 & 8 & 97 & $94(R)$ \\
\hline 12 & $\mathbf{1 a}(10)$ & $4-\mathrm{O}_{2} \mathrm{NC}_{6} \mathrm{H}_{3} \mathrm{CO}_{2} \mathrm{H}(10)$ & $\mathrm{Ph}_{3} \mathrm{MePBr} / \mathrm{Gly}(1 / 2)$ & 25 & 8 & 95 & $90(R)$ \\
\hline 13 & $\mathbf{1 a}(10)$ & Imidazole (10) & $\mathrm{Ph}_{3} \mathrm{MePBr} / \mathrm{Gly}(1 / 2)$ & 25 & 8 & 94 & $66(R)$ \\
\hline 14 & $\mathbf{1 a}(10)$ & DMAP (10) & $\mathrm{Ph}_{3} \mathrm{MePBr} / \mathrm{Gly}(1 / 2)$ & 25 & 8 & 90 & $50(R)$ \\
\hline 15 & $\mathbf{1 a}(20)$ & $3,4-(\mathrm{OMe})_{2} \mathrm{C}_{6} \mathrm{H}_{3} \mathrm{CO}_{2} \mathrm{H}(20)$ & $\mathrm{Ph}_{3} \mathrm{MePBr} / \mathrm{Gly}(1 / 2)$ & 25 & 8 & 94 & $92(R)$ \\
\hline 16 & $1 \mathbf{a}(5)$ & $3,4-(\mathrm{OMe})_{2} \mathrm{C}_{6} \mathrm{H}_{3} \mathrm{CO}_{2} \mathrm{H}(5)$ & $\mathrm{Ph}_{3} \mathrm{MePBr} / \mathrm{Gly}(1 / 2)$ & 25 & 24 & 89 & $86(R)$ \\
\hline 17 & $\mathbf{1 a}(10)$ & $3,4-(\mathrm{OMe})_{2} \mathrm{C}_{6} \mathrm{H}_{3} \mathrm{CO}_{2} \mathrm{H}(10)$ & $\mathrm{Ph}_{3} \mathrm{MePBr} / \mathrm{Gly}(1 / 2)$ & 10 & 8 & 10 & $66(R)$ \\
\hline 18 & $\mathbf{1 b}(10)$ & $3,4-(\mathrm{OMe})_{2} \mathrm{C}_{6} \mathrm{H}_{3} \mathrm{CO}_{2} \mathrm{H}(10)$ & $\mathrm{Ph}_{3} \mathrm{MePBr} / \mathrm{Gly}(1 / 2)$ & 25 & 8 & 94 & $88(R)$ \\
\hline 19 & 1c (10) & $3,4-(\mathrm{OMe})_{2} \mathrm{C}_{6} \mathrm{H}_{3} \mathrm{CO}_{2} \mathrm{H}(10)$ & $\mathrm{Ph}_{3} \mathrm{MePBr} / \mathrm{Gly}(1 / 2)$ & 25 & 8 & 93 & $90(R)$ \\
\hline 20 & ent-1a (10) & $3,4-(\mathrm{OMe})_{2} \mathrm{C}_{6} \mathrm{H}_{3} \mathrm{CO}_{2} \mathrm{H}(10)$ & $\mathrm{Ph}_{3} \mathrm{MePBr} / \mathrm{Gly}(1 / 2)$ & 25 & 8 & 95 & $94(S)$ \\
\hline
\end{tabular}

a Abbreviations: $\mathrm{ChCl}=$ choline chloride; DMAP $=4-N, N$-dimethylaminopyridine; $\mathrm{Gly}=$ glycerol; HDA $=$ hexanedioic acid; $\mathrm{TBAB}=$ tetra- $n$ butylammonium bromide

${ }^{\mathrm{b}}$ Isolated yield after flash chromatography.

${ }^{\mathrm{c}}$ Enantioselectivity determined by chiral HPLC. 
${ }^{\mathrm{d}}$ Absolute configuration assigned by the order of elution of the enantiomers in chiral HPLC.

Once the most convenient DES $\left(\mathrm{Ph}_{3} \mathrm{MePBr} / \mathrm{Gly}, 1 / 2\right.$ molar ratio) and additive $\left[3,4-(\mathrm{OMe})_{2} \mathrm{C}_{6} \mathrm{H}_{3} \mathrm{CO}_{2} \mathrm{H}, 10\right.$ $\mathrm{mol} \%$ ) were established, we studied the influence of the amount of organocatalyst 1a. Increasing the loading of 1a up to $20 \mathrm{~mol} \%$ showed almost no influence in yield or enantioselectivity for adduct $(R)-\mathbf{4 a a}$, whereas diminishing it down to $5 \mathrm{~mol} \%$ gave rise to a lower yield and $e e$ in a much longer reaction time (Table 1, entries 15 and 16). In addition, lowering the reaction temperature down to $10^{\circ} \mathrm{C}$ resulted in a very slow reaction rate and an enantioselection of only $66 \%$ (Table 1 , entry 17 ).

With the most appropriate catalyst loading, additive, DES and reaction temperature determined, we explore the organocatalytic behaviour of the other chiral carbamatemonoprotected trans-cyclohexane-1,2-diamines $\mathbf{1 b}$ and 1c, bearing a benzyloxycarbonyl (Cbz) and a fluorenylmethoxycarbonyl (Fmoc) protecting group, respectively. Their performance in the model reaction was not superior to 1a, affording adduct $(R)-\mathbf{4 a a}$ in good yields, but with lower enantioselectivities (Table 1, entries 18 and 19). Finally, we carried out a blank reaction in absence of organocatalyst $\mathbf{1}$ but in the presence of additive, observing no reaction.

In order to achieve opposite enantioselectivities to those obtained using organocatalyst 1a, we obtained its enantiomer ent-1a, following an identical procedure but starting from $(1 R, 2 R)$-cyclohexane-1,2-diamine. ${ }^{12 \mathrm{r}}$ Using this mono-Boc-protected diamine as organocatalyst, under the most convenient reaction conditions [ent-1a (10 mol\%), 3,4-(OMe) ${ }_{2} \mathrm{C}_{6} \mathrm{H}_{3} \mathrm{CO}_{2} \mathrm{H}$ (10 mol\%), $\mathrm{Ph}_{3} \mathrm{MePBr} / \mathrm{Gly}$ $(1 / 2$ molar ratio), rt], the expected enantiomeric adduct $(S)$-4aa was obtained in identical absolute value of opposite enantioselectivity than when using 1a as organocatalyst (Table 1, entry 20).

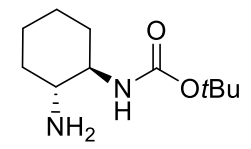

ent-1a

We subsequently explore the extension of the procedure to other aldehydes and $N$-substituted maleimides, employing the above mentioned optimized reaction conditions (Table 2). As in the case of the model reaction, the absolute configuration of the resulting succinimides was assigned according to the elution order of their enantiomers in chiral HPLC when compared to the literature. ${ }^{12 \mathrm{r}}$

Thus, when isobutyraldehyde reacted with $\mathrm{N}$ phenylmaleimides bearing halogens on the phenyl ring, such as a chloro or a bromo atom at the 3- or 4-positions $(\mathbf{3 b}, \mathbf{3 c}$ and $\mathbf{3 d})$, the corresponding succinimides $(R)-\mathbf{4 a b}$, $(R)$-4ac and $(R)$-4ac were obtained in very high yields in 70,87 and $86 \% e e$, respectively (Table 2, entries 2-4). In addition, when an acyl group was present onto the phenyl ring of the maleimide, as in the case of $\mathbf{3 e}$, the enantioselectivity for the corresponding succinimide $(R)$ 4ae was $72 \%$ ee in a slightly lower yield (Table 2, entry $5)$. A similar enantioselectivity for $(R)$-4af was observed when an electron-releasing group, such as a methoxy, was present at the 4-position (3f) (Table 2, entry 6)

Non- $N$-arylated maleimides were also employed for the conjugate addition with isobutyraldehyde. Thus, $N$ benzylmaleimide (3g) and $N$-methylmaleimide (3h) gave succinimides $(R)-\mathbf{4 a g}$ and $(R)-\mathbf{4 a h}$ in high yields but in moderate 63 and $66 \%$ ee, respectively (Table 2, entries 7 and 8). In addition, the simple maleimide (3i) was also used as Michael acceptor, affording $(R)-4 a i$ in $90 \%$ yield and $67 \%$ ee (Table 2, entry 9).

Other $\alpha, \alpha$-disubstituted aldehydes were employed for the organocatalyzed conjugate addition reaction to $\mathrm{N}$ phenylmaleimide. Thus, 2-ethylbutanal (3b) afforded succinimide $(R)-\mathbf{4 b a}$ in moderate yield and enantioselectivity (Table 2, entry 10). However, cyclopentanecarbaldehyde (2c) gave almost a quantitative yield of $(R)-4$ ca in $87 \%$ ee (Table 2, entry 11 ), something very different than when using cyclohexanecarbaldehyde (2d), which afforded the corresponding adduct $(R)-\mathbf{4 d a}$ with an enantioselection of only $31 \%$ (Table 2 , entry 12 ). Moreover, when a different $\alpha, \alpha$-disubstituted aldehyde such as 2-phenylpropanal (2e) was employed, the final adduct was obtained in a 4/1 diastereomeric ratio with an enantioselection of $85 \%$ for the diastereomer $(S, R)$-4ea and $10 \%$ for $(R, R)$-4ea (Table 2, entry 13). Furthermore, the use of an $\alpha$-monosubstituted aldehyde such as propanal (2f), allowed obtaining the adducts as a 1.4/1 mixture of diastereomers, with enantioselections of $50 \%$ for $(R, R)$ - and $(S, R)-\mathbf{4 f a}$ (Table 2, entry 14$)$.

Obviously, the possibility of reusing the DES is the cornerstone of a synthetic methodology performed using these neoteric solvents. Therefore, we explore the reusability of the DES, and the catalytic system, carrying out different reaction cycles of the model conjugate addition reaction performed under the best reaction conditions depicted in Table 2, entry 1 . Thus, once the reaction was finished, a $4 / 1 \mathrm{v} / \mathrm{v}$ mixture of ethyl ether $n$ hexane was added and the resulting mixture was stirred vigorously. After the two layers settled down, the upper one, containing the final adduct, was separated. Attempting to directly reuse the lower DES layer in other reaction by adding new aldehyde and maleimide resulted in low yields and just moderate enantioselectivities of the resulting adduct $(R)$-4aa. After several attempts, it was found that refreshing the catalytic system by addition of new additive (but no new chiral organocatalyst) to the recovered DES allowed obtaining almost identical enantioselectivity and yield of $(R)$-4aa than when used for the first time. Following this recovery procedure, the DES (containing the organocatalyst 1a) was suitable to be reused four times without diminishing its enantioinduction (Table 3). However, a fifth reaction cycle gave rise to a lowering in the catalytic activity. 
Table 2. Enantioselective conjugate addition of aldehydes to maleimides organocatalyzed by $\mathbf{1 a}$ in a DES.

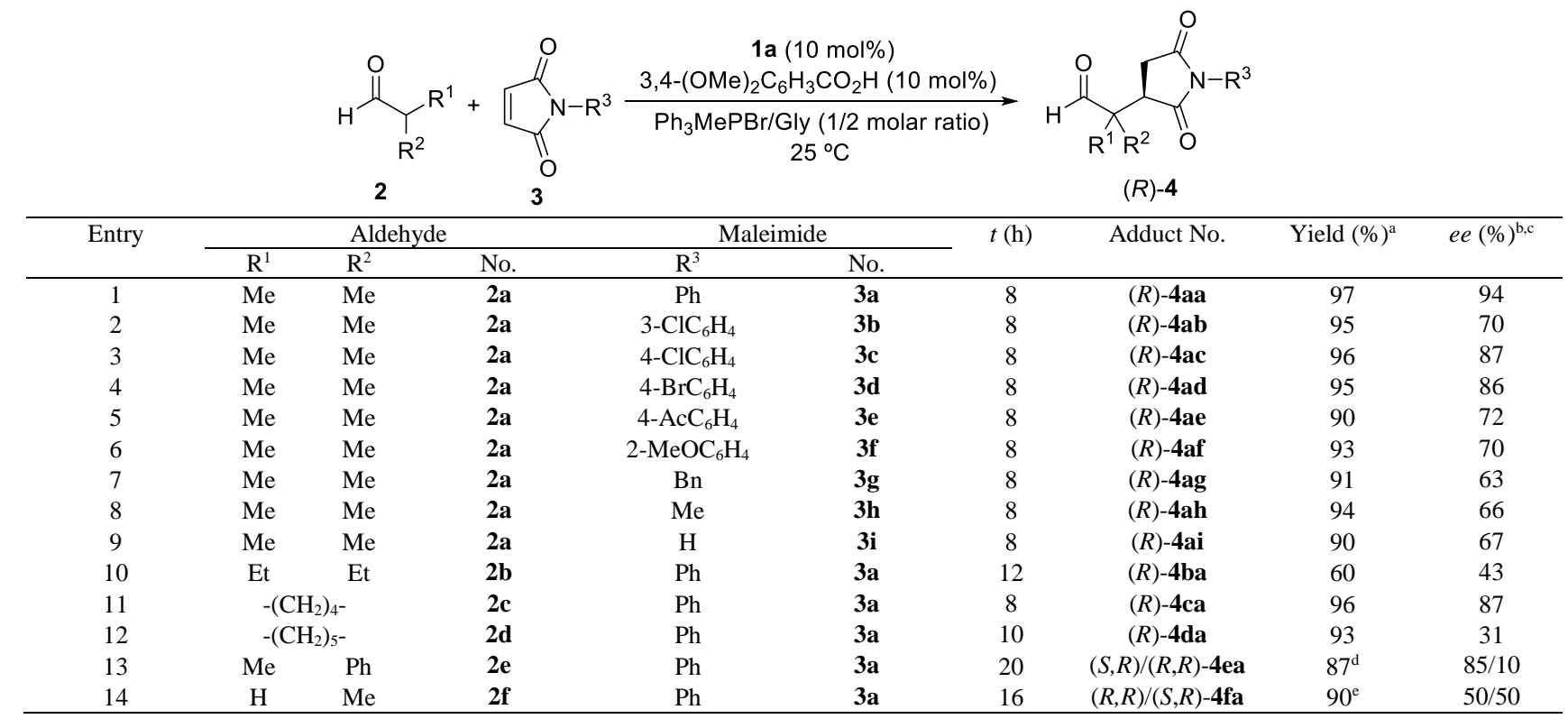

${ }^{a}$ Isolated yield after flash chromatography.

${ }^{\mathrm{b}}$ Enantioselectivities determined by chiral HPLC.

${ }^{\mathrm{c}}$ Absolute configuration assigned by the order of elution of the enantiomers in chiral HPLC.

${ }^{\mathrm{d}}$ Mixture of diastereomers 4/1 determined by ${ }^{1} \mathrm{H}$ NMR $(300 \mathrm{MHz})$ in the reaction crude.

${ }^{\mathrm{e}}$ Mixture of diastereomers $1.4 / 1$ determined by ${ }^{1} \mathrm{H}$ NMR (300 MHz) in the reaction crude.

Table 3. Recycle experiments. Yields and $e e$ 's of $(R)-4 a a$ after consecutive reaction cycles.

\begin{tabular}{ccc}
\hline Reaction cycle & ${\text { Yield }(\%)^{\mathrm{a}}}^{\mathrm{a}}$ & $e e(\%)^{\mathrm{b}}$ \\
\hline 1 & 97 & 94 \\
2 & 95 & 94 \\
3 & 93 & 93 \\
4 & 76 & 92 \\
5 & 60 & 84 \\
\hline
\end{tabular}

${ }^{\text {a }}$ Isolated yield after flash chromatography.

${ }^{\mathrm{b}}$ Enantioselectivitity determined by chiral HPLC.

\section{Conclusions}

It can be concluded that DESs can be used as reusable solvents in the enantioselective conjugate addition of aldehydes, mainly $\alpha, \alpha$-disubstituted, to $N$-substituted maleimides, affording enantioenriched substituted succinimides. Carbamate-monoprotected trans-cyclohexa1,2-diamines are employed as enantiomerically pure organocatalysts, the mono-Boc-substituted derivative affording the best results. The reaction is carried out in the presence of a carboxylic acid as additive at room temperature. Once the reaction is completed, the final adduct can be separated by extraction, and the DES, retaining the organocatalyst, can be reused up to four times after addition of fresh additive, keeping its enantiodifferentiation activity.

\section{Experimental}

4.1. General. All reagents were commercially available and used without further purification. Organocatalysts $\mathbf{1}$ were obtained as described. ${ }^{12 r}$ All known adducts $\mathbf{4}$ were characterized by spectroscopic methods. ${ }^{12 \mathrm{r}}$ Enantioselectivities and absolute configurations were determined on the reaction crude by HPLC analyses ${ }^{12 \mathrm{r}}$ on an Agilent 1100 series equipped with chiral columns (Chiralcel ODH: 4aa, 4ab, 4ac, 4ad, 4ca, 4da, 4ea; ${ }^{12 l}$ Chiralcel AD-H: 4af; Chiralpak AS-H: 4ae, 4ah, 4ba; Chiralpak AD-H: 4ag, 4ai, 4fa), using mixtures of $n$-hexane/isopropyl alcohol as the mobile phase, at $25{ }^{\circ} \mathrm{C}$. Analytical TLC was performed on Schleicher \& Schuell F1400/LS silica gel plates and the spots were visualised under UV light. For chromatography we employed Merck silica gel 60 (0.063-0.2 mm).

4.2. General procedure for the preparation of DESs. A mixture of the two components, with the previously specified molar ratio, was added to a round bottom flask and the mixture was stirred for $60 \mathrm{~min}$ in a temperature range between 65 and $80^{\circ} \mathrm{C}$, obtaining the corresponding DES. ${ }^{13}$ 
4.3. Enantioselective conjugate addition reaction. General procedure. To a mixture of the catalyst $1(0.02$ $\mathrm{mmol})$, additive $(0.02 \mathrm{mmol})$, and maleimide $(0.2 \mathrm{mmol})$ in the corresponding DES $(0.5 \mathrm{~mL})$ was added the aldehyde $(0.4 \mathrm{mmol})$ and the reaction was vigorously stirred during the necessary reaction time (TLC, Table 2) at rt. $2 \mathrm{M} \mathrm{HCl}(10 \mathrm{~mL})$ was added and the mixture was extracted with AcOEt $(3 \times 10 \mathrm{~mL})$. The combined organics were washed with aq $\mathrm{NaHCO}_{3}(2 \times 10 \mathrm{~mL})$, dried $\left(\mathrm{MgSO}_{4}\right)$ and evaporated (15 torr), and the resulting crude was purified by flash chromatography (hexane/EtOAc gradients) affording adduct 4 .

4.4. Recycle experiments. To a mixture of the catalyst $1 \mathrm{a}$ (4.3 mg, $0.02 \mathrm{mmol})$, 3,4-dimethoxybenzoic acid (3,7 mg, $0.02 \mathrm{mmol}$ ), and $N$-phenylmaleimide $(34.6 \mathrm{mg}, 0.2 \mathrm{mmol}$ ) in $\mathrm{Ph}_{3} \mathrm{MePBr} / \mathrm{Gly}(1 / 2$ molar ratio, $0.5 \mathrm{~mL})$ was added isobutyraldehyde $(36.5 \mu \mathrm{L}, 0.4 \mathrm{mmol})$ and the reaction was vigorously stirred for $8 \mathrm{~h}$ at $\mathrm{rt}$. After this period, a mixture of ethyl ether $n$-hexane $(4 / 1, \mathrm{v} / \mathrm{v}, 3 \mathrm{~mL})$ was added and the mixture was stirred for $2 \mathrm{~min}$. The stirring was stopped to allow phase separation and the upper organic layer was removed through settling. This extractive procedure was repeated three times. The combined organic extracts where washed $\left(\mathrm{NaHCO}_{3}\right.$ aq, 10 $\mathrm{mL})$, dried $\left(\mathrm{MgSO}_{4}\right)$, evaporated (15 torr) and purified by flash chromatography on silica gel (hexane/EtOAc gradients) yielding $(R)$-4aa. The DES layer, where catalyst 1a remained dissolved, was evaporated in vacuo to remove volatile solvent residues (15 torr) and the catalytic system was regenerated by 3,4dimethoxybenzoic acid addition (3,7 $\mathrm{mg}, 0.02 \mathrm{mmol})$. A further run was performed with this DES, adding new isobutyraldehyde and $\mathrm{N}$-phenylmaleimide. This reaction mixture was subjected again to the above described procedure and further reaction cycles were repeated using the same DES phase.

\section{Acknowledgments}

We thank the financial support from the Spanish Ministerio de Economía y Competitividad (project CTQ2015-66624-P) and the University of Alicante (VIGROB-173 and UAUSTI14). J. F.-F. particularly acknowledges the Vicerrectorado de Investigación y Transferencia de Conocimiento of the University of Alicante for a fellowship.

\section{References}

1. Comprehensive Enantioselective Organocatalysis. Dalko, P. I., Ed.; Wiley-VCH: Weinheim, Germany, 2013.

2. (a) Liu, P.; Hao, J.-W.; Mo, L.-P.; Zhang, Z.-H. RSC Adv. 2015, 5, 48675-48704; (b) Alonso, D. A.; Baeza, A.; Chinchilla, R.; Guillena, G.; Pastor, I. M.; Ramón,
D. J. Eur. J. Org. Chem. 2016, 612-632; (c) Khandelwal, S.; Tailor, Y. K.; Kumar, M. J. Mol. Liq. 2016, 215, 345-386; (d) Guajardo, N.; Müller, C. R.; Schrebler, R.; Carlesi, C.; Domínguez de María, P. ChemCatChem 2016, 8, 1020-1027.

3. (a) Zhang, Q.; De Oliveira Vigier, K.; Royer, S.; Jerome, F. Chem. Soc. Rev. 2012, 41, 7108-7146; (b) Francisco, M.; van den Bruinhorst, A.; Kroon, M. C. Angew. Chem., Int. Ed. 2013, 52, 3074-3085; (c) Tang, B.; Row, K. H. Monatsh. Chem. 2013, 144, 1427-1454; (d) Paiva, A.; Craveiro, R.; Aroso, I.; Martins, M.; Reis, R. L.; Duarte, A. R. C. ACS Sustainable Chem. Eng. 2014, 2, 1063-1071; (e) Smith, E. L.; Abbott, A. P.; Ryder, K. S. Chem. Rev. 2014, 114, 11060-11082.

4. (a) Müller, C. R.; Meiners, I.; Domínguez de María, P. RSC Adv. 2014, 4, 46097-46101; (b) Müller, C. R.; Rosen, A.; Domínguez de María, P. Sustainable Chem. Processes 2015, 3, 1-8.

5. Massolo, E.; Palmieri, S.; Benaglia, M.; Capriati, V.; Perna, F. M. Green Chem. 2016, 18, 792-797.

6. Martínez, R.; Berbegal, L.; Guillena, G.; Ramón, D. J. Green Chem. 2016, 18, 1724-1730.

7. Chauhan, P.; Kaur, J.; Chimni, S. S. Chem. Asian J. 2012, 8, 328-346.

8. (a) Ando, Y.; Fuse, E.; Figg, W. D. Clin. Cancer Res. 2002, 8, 1964-1973; (b) Freiberg, C.; Brunner, N. A.; Schiffer, G.; Lampe, T.; Pohlmann, J.; Brands, M.; Raabe, M.; Haebich, D.; Ziegelbauer, K. J. Biol. Chem. 2004, 279, 26066-26073; (c) Isaka, M.; Rugseree, N.; Maithip, P.; Kongsaeree, P.; Prabpai, S.; Thebtaranonth, Y. Tetrahedron 2005, 61, 5577-5583; (d) Uddin, J.; Ueda, K.; Siwu, E. R. O.; Kita, M.; Uemura, D. Bioorg. Med. Chem. 2006, 14, 6954-6961; (e) Aboul-Enein, M. N.; El-Azzouny, A. A.; Saleh, O. A.; Maklad, Y. A. Mini-Rev. Med. Chem. 2012, 12, 671-700.

9. (a) Nöth, J.; Frankowski, K. J.; Neuenswander, B.; Aubé, J.; Reiser, O. J. Comb. Chem. 2008, 10, 456459; (b) Fenster, E.; Hill, D.; Reiser, O.; Aube, J. Beilstein J. Org. Chem. 2012, 8, 1804-1813.

10. (a) Reddy, P. A.; Hsiang, B. C. H.; Latifi, T. N.; Hill, M. W.; Woodward, K. E.; Rothman, S. M.; Ferrendelli, J. A.; Covey, D. F. J. Med. Chem. 1996, 39, 1898-1906; (b) Spaltenstein, A.; Almond, M. R.; Bock, W. J.; Cleary, D. G.; Furfine, E. S.; Hazen, R. J.; Kazmierski, W. M.; Salituro, F. G.; Tung, R. D.; Wright, L. L. Bioorg. Med. Chem. Lett. 2000, 10, 1159-1162; (c) Barnes, D. M.; Ji, J.; Fickes, M. G.; Fitzgerald, M. A.; King, S. A.; Morton, H. E.; Plagge, F. A.; Preskill, M.; Wagaw, S. H.; Wittenberger, S. J.; Zhang, J. J. Am. Chem. Soc. 2002, 124, 13097-13105; (d) Tang, K.; Zhang, J.-T. Neurol. Res. 2002, 24, 473478; (e) Kazmierski, W. M.; Andrews, W.; Furfine, E.; Spaltenstein, A.; Wright, L. Bioorg. Med. Chem. Lett. 2004, 14, 5689-5692; (f) Das Sarma, K.; Zhang, J.; Huang, Y.; Davidson, J. G. Eur. J. Org. Chem. 2006, 3730-3737; (g) Chauhan, D.; Catley, L.; Li, G.; 
Podar, K.; Hideshima, T.; Velankar, M.; Mitsiades, C.; Mitsiades, N.; Yasui, H.; Letai, A.; Ovaa, H.; Berkers, C.; Nicholson, B.; Chao, T.-H.; Neuteboom, S. T. C.; Richardson, P.; Palladino, M. A.; Anderson, K. C. Cancer Cell 2005, 8, 407-419.

11. (a) Serdyuk, O. V.; Heckel, C. M.; Tsogoeva, S. B. Org. Biomol. Chem. 2013, 11, 7051-7071; (b) Desmarchelier, A.; Coeffard, V.; Moreau, X.; Greck, C. Tetrahedron 2014, 70, 2491-2513.

12. (a) Zhao, G.-L.; Xu, Y.; Sundén, H.; Eriksson, L.; Sayah, M.; Cordova, A. Chem. Commun. 2007, 734735; (b) Yu, F.; Jin, Z.; Huang, H.; Ye, T.; Liang, X.; Ye, J. Org. Biomol. Chem. 2010, 8, 4767-4774; (c) Bai, J.-F.; Peng, L.; Wang, L.-1.; Wang, L.-X.; Xu, X.Y. Tetrahedron 2010, 66, 8928-8932; (d) Xue, F.; Liu, L.; Zhang, S.; Duan, W.; Wang, W. Chem. Eur. J. 2010, 16, 7979-7982; (e) Miura, T.; Masuda, A.; Ina, M.; Nakashima, K.; Nishida, S.; Tada, N.; Itoh, A. Tetrahedron: Asymmetry 2011, 22, 1605-1609; (f) Ma, Z.-w.; Liu, Y.-X.; Li, P.-l.; Ren, H.; Zhu, Y.; Tao, J.-c. Tetrahedron: Asymmetry 2011, 22, 1740-1748; (g) Ma, Z.-W.; Liu, Y.-X.; Zhang, W.-J.; Tao, Y.; Zhu, Y.; Tao, J.-C.; Tang, M.-S. Eur. J. Org. Chem. 2011, 6747-6754; (h) Nugent, T. C.; Sadiq, A.; Bibi, A.; Heine, T.; Zeonjuk, L. L.; Vankova, N.; Bassil, B. S. Chem. Eur. J. 2012, 18, 4088-4098; (i) Avila, A.; Chinchilla, R.; Nájera, C. Tetrahedron: Asymmetry 2012, 23, 1625-1627; (j) Avila, A.; Chinchilla, R.; Gómez-Bengoa, E.; Nájera, C. Eur. J. Org. Chem. 2013, 5085-5092; (k) Orlandi, S.; Pozzi, G.; Ghisetti, M.; Benaglia, M. New J. Chem. 2013, 37, 4140-4147; (1) Kokotos, C. G. Org. Lett. 2013, 15, 2406-2409; (m) Muramulla, S.; Ma, J.-A.; Zhao, J. C.-G. Adv. Synth. Catal. 2013, 355, 1260-1264; (n) Yang, W.; Jiang, K.Z.; Lu, X.; Yang, H.-M.; Li, L.; Lu, Y.; Xu, L.-W. Chem. Asian J. 2013, 8, 1182-1190; (o) Avila, A.; Chinchilla, R.; Gómez-Bengoa, E.; Nájera, C. Tetrahedron: Asymmetry 2013, 24, 1531-1535; (p) Durmaz, M.; Sirit, A. Tetrahedron: Asymmetry 2013, 24, 1443-1448; (q) Flores-Ferrándiz, J.; Chinchilla, R. Tetrahedron: Asymmetry 2014, 25, 1091-1094; (r) Flores-Ferrándiz, J.; Fiser, B.; Gómez-Bengoa, E.; Chinchilla, R. Eur. J. Org. Chem. 2015, 1218-1225; (s) Vizcaíno-Milla, P.; Sansano, J. M.; Nájera, C.; Fiser, B.; Gómez-Bengoa, E. Synthesis 2015, 47, 2199-2206; (t) Fernandes, T. d. A.; Vizcaíno-Milla, P.; Ravasco, J. M. J. M.; Ortega-Martinez, A.; Sansano, J. M.; Nájera, C.; Costa, P. R. R.; Fiser, B.; GómezBengoa, E. Tetrahedron: Asymmetry 2016, 27, 118122.

13. (a) Shahbaz, K.; Mjalli, F. S.; Hashim, M. A.; Al Nashef, I. M. Energy Fuels 2011, 25, 2671-2678; (b) Yusof, R.; Abdulmalek, E.; Sirat, K.; Abdul Rahman, M. B. Molecules 2014, 19, 8011-8026; (c) García, G.; Aparicio, S.; Ullah, R.; Atilhan, M. Energy Fuels 2015, 29, 2616-2644. 